Tequio 1(1), 2017: 39-43

ISSN: 2594-0546

\title{
DIVERSIDAD CULTURAL Y ESTILOS COGNITIVOS
}

\author{
Laura Bensasson ${ }^{1}$
}

Fecha de recepción: 4 de noviembre de 2016

Fecha de aceptación: 25 de mayo de 2017

Resumen - El habla y el pensamiento tienen un mismo sustrato orgánico: los hemisferios cerebrales, que se encargan de procesar la información que reciben a través de los sentidos y le dan significado con base en la cultura y la lengua que utilizamos para ponerla en palabras. Pero esta información no se procesa de la misma manera en todas las culturas y en lenguas diferentes. ¿Qué impacto puede tener un modelo educativo que pretende ser universal en niños con modelos cognitivos distintos? ¿Es que una educación occidentalizada y universalista es conveniente para todo tipo de cultura y de lengua?

\section{Palabras clave:}

Hemisferios cerebrales, estilos cognitivos, lenguaje, aprendizaje, diversidad cultural.
Abstract - Speech and thought have a single organic substrate: the cerebral hemispheres, which are responsible for processing the information received through the senses and give it meaning based on the culture and the language we use to put it into words. But this information is not processed in the same way in all cultures and with different languages. What impact can have an educational model that aims to be universal in children with different cognitive models? Is that an education Westernized and Universalist is suitable for all type of culture and of language?

\section{Keywords:}

Cerebral hemispheres, cognitive styles, language, learning, cultural diversity. 


\section{El habla y la mente}

Aucho se ha hablado de la importancia que en la educación escolarizada debería tener la conservación del idioma que se aprende en el hogar, pues una lengua no es sólo un medio de comunicación, sino que impacta en las funciones mentales relacionadas con el conocimiento.

La percepción del habla requiere de diferentes procesos que enlazan audición y pensamiento para la codificación de las señales sonoras. La comprensión de estas señales incluye la información léxica, sintáctica y contextual necesarias para interpretar su significado, pues además de las palabras concretas -que definen objetos y son más fáciles de reconocer y aprendery las abstractas -que expresan ideas o conceptos-, existen las "funcionales" (adverbios, conjunciones, etcétera), que no poseen ningún significado semántico. La psicolingüística trata justamente de descubrir los procesos psicológicos que llevan a la comprensión, producción y adquisición del lenguaje hablado y escrito (Berko y Bernstein, 1999).

En el siglo XIX Paul Broca y Karl Wernicke estudiaron los efectos de las lesiones cerebrales en el procesamiento y la comprensión del lenguaje, descubriendo la existencia de asimetrías entre los dos hemisferios. Parecía entonces que el lenguaje estaba localizado en el izquierdo y en estrecha combinación con el uso de la mano diestra, pues los hemisferios procesan los estímulos auditivos en función de su naturaleza: si se trata de acordes musicales y melodías, el que actúa es el derecho; pero los sonidos relacionados con el lenguaje (los fonemas) llegan al izquierdo. ${ }^{2}$ Sin embargo, ambos se activan durante el proceso lingüístico, lo cual nos lleva a pensar que éste no se limita al hemisferio dominante; los dos concurren y parecen complementarse para los distintos aspectos del lenguaje, pues aun cuando éste suele localizarse en el hemisferio izquierdo, algunas habilidades (como la interpretación del discurso y el lenguaje figurativo y humorístico) parecen estar mediadas por el derecho (Berko y Bernstein, 1999).

Lo anterior entraña importantes cuestionamientos respecto de la educación, por el énfasis en la adquisición de la habilidad verbal y del pensamiento analítico, a expensas de las capacidades no verbales. Cada mitad del cerebro es capaz de percibir, aprender, recordar y sentir independientemente de la otra, pero existen diferencias en el modo en que cada una procesa la información entrante (Springer y Deutsch, 1994, p. 20).

Aunque físicamente simétricos, se sabe ahora que los hemisferios cerebrales no asimilan la información de la misma manera, sino que se reparten tareas: el izquierdo (HI) se encarga de los procesos analíticos, el procesamiento secuencial de la información y la producción y comprensión del lenguaje; el derecho (HD) se interesa por las imágenes, las sensaciones, las emociones, las informaciones espaciales y el procesamiento simultáneo de la información. Se ha hablado incluso de una dominancia genética de uno de los dos hemisferios; ¿podría hablarse también de una dominancia cultural?

Existen, naturalmente, estructuras y mecanismos unificadores que permiten armonizar los hemisferios, integrando las formas verbales y espaciales del pensamiento, pero la transferencia de datos de uno a otro puede ser inhibida por un conflicto intrapsíquico como en los "dobles mensajes"-y quizá en el bilingüismo conflictivo, como en el caso de los hablantes de lenguas socialmente estigmatizadas.

Es a partir de los estudios sobre la lateralización que se ha sugerido la existencia de dos estilos cognitivos relacionados con los dos hemisferios y con las distintas formas de inteligencia postuladas por J. P. Guilford a mediados del siglo XX: el "cerebro izquierdo" corresponde al pensamiento convergente, fundamentalmente lógico, verbal, analítico, temporal y deductivo, pero limitado

\footnotetext{
2 Para Jakobson (1988), el hecho de que el oído derecho reciba mejor los componentes del habla mientras que el izquierdo domina los sonidos no verbales -ya sean notas musicales o ruidos-, muestra que los sonidos del habla constituyen una categoría particular ante la cual el cerebro reacciona de manera específica. Esta peculiaridad consiste en que tales sonidos funcionan como "acarreadores de significado".
} 
cuando se trata de buscar soluciones a problemas nuevos. El pensamiento divergente o creativo, propio del "cerebro derecho", en cambio, es viso-espacial, simultáneo, analógico, sintético, intuitivo, metafórico, imaginativo. Sin embargo, las pruebas que miden el cociente intelectual van dirigidas hacia las aptitudes del $\mathrm{HI}$, mientras que se carece de instrumentos de evaluación diagnóstica para las habilidades del HD, esenciales para la actividad creativa.

Se ha comprobado que los factores genéticos pueden determinar la dominación de uno u otro hemisferio, pero ¿corresponde la especialización observada a distintas formas de pensamiento? ¿Cuál es el papel de la experiencia y de los factores ambientales? ¿Es verdad que los sistemas educativos occidentalizados han recalcado el pensamiento del cerebro izquierdo y descuidado el potencial del derecho? Se han realizado estudios que confirman las variaciones en los estilos cognitivos entre distintas culturas, pero no sabemos a ciencia cierta si ello dependa de diferencias en el uso de los hemisferios.

El psicólogo Robert Ornstein, interesado en la naturaleza de la conciencia y su relación con los hemisferios, identifica al izquierdo con el pensamiento occidental tecnológico y racional, y al derecho con el oriental, intuitivo y místico, enfatizando que en la escuela dedican la mayor parte del tiempo a entrenar a los estudiantes en aptitudes propias del primero, con el resultado de que hemos aprendido a mirar fragmentos inconexos, en lugar de obtener una visión integral (Ornstein, 1970).

\section{Percepción y cultura: los estilos cognitivos}

La percepción es un fenómeno complejo en el que influyen afectos, categorías socialmente aceptadas, contextos, intereses. Es un acto individual, condicionado en gran medida por el desarrollo de las relaciones sociales y por el lenguaje. [...] Así, nuestra "objetividad" es la percepción de individuos históricamente condicionados (Paoli, 2002, p. 21).
Muchas cuestiones insolubles desde los enfoques cognitivos 0 psicolingüísticos encuentran una explicación más plausible desde las perspectivas socioculturales, especialmente para comprender los efectos de las presiones ejercidas sobre quienes aprenden una segunda lengua, cuando el valor social asociado al idioma materno es inferior.

La cultura -escribe Buxó Rey (1984, pp. 33-34)es el sistema de conocimiento a partir de cuyos significados el ser humano tamiza y selecciona su comprensión de la realidad. [...] En tanto que creación de la mente humana, la cultura representa la realidad por medio de ideas y conceptos.

La anterior no es la única definición de cultura, pero vale recalcar con Buxó Rey la fuerte influencia de la vida social sobre la cognición y el comportamiento humanos, y, por lo tanto, sobre el lenguaje.

Después de discutir si las diferencias culturales son indicadores suficientes de las variaciones en las formas de pensar, la antropología cognitiva y experimental replantea la relación cognicióncultura en términos de procesos y no de contenidos. La aplicación de los principios de Jean Piaget en las indagaciones realizadas en sociedades primitivas muestra, por ejemplo, que la lógica formal -base del conocimiento científico occidental- no surge de un modo espontáneo, sino que es producto de un método educativo en el cual la alfabetización y la educación desempeñan un rol fundamental. De manera que podemos definir la cognición como "un proceso selectivo dinámico cuyas estructuras son el resultado de la interacción adaptativa entre sus propiedades, la cultura y el ambiente" (Buxó Rey, 1984, p. 37).

En las sociedades "tecno-económicamente más avanzadas", afirma este autor, el formalismo abstracto ha pasado a ser la estructura ideológica dominante y se asocia con el estilo cognitivo que estas comunidades identifican como "inteligencia superior". Pero un 
pensamiento correcto no se relaciona necesariamente con la lógica formal, pues una cosa es el estilo cognitivo que más se valora socialmente, y otra el más adecuado para las funciones socioculturales habituales.

El modo cognitivo determina la ordenación lógica y simbólica en la que se apoyan los datos culturales para organizar coherentemente los sistemas de conocimientos y para codificarlos en lenguajes formales, mas ello no implica la existencia de una verdad objetiva única, pues el conocimiento, al igual que la lengua, es una construcción arbitraria, validada sólo por un consenso relativo al sistema conceptual y al conjunto de valores culturales. Por lo tanto, insiste Buxó Rey (1984, pp. 54-55), hay que cambiar el énfasis "de la estructura del 'mundo real' a la estructura de nuestra experiencia del mundo". El estudio de la relación entre los procesos cognitivos y culturales que dan forma, organización y significado a la experiencia y al comportamiento humano -concluye- permite descubrir modos diferentes de pensar la realidad, abriendo la posibilidad a otras maneras de existir.

En resumen:

Los estilos cognitivos no representan propiedades de una forma de pensar, sino actividades intelectuales funcionales en contextos socioculturales específicos [...] Por ello cabe concluir que las formas diversas de procesar la realidad corresponden al tipo de inteligencia que cada grupo social o cultural considera apropiado para resolver sus necesidades adaptativas e ideológicas (Buxó Rey, 1984, p. 41).

\section{Los lenguajes del saber}

Los sonidos del habla actúan necesariamente como transportadores de sentido. Sonido y sentido son una dualidad indisoluble, pero el sentido no se encuentra en los sonidos aislados, sino en la manera en que éstos se combinan (Jakobson, 1996, p. 95). Más aún: los significados de una lengua no dependen sólo de su estructura, sino que están relacionados con el contexto y la cultura, pues implican "un modo de indicar, presuponer o proyectar sobre el contexto presente creencias, sentimientos, identidades 0 acontecimientos" (Duranti, 2000, p. 65).

Podemos, pues, definir a la semántica como el estudio de "los sistemas por medio de los cuales las percepciones, conceptos e ideas se codifican en forma de palabras", o el estudio de "los sistemas por medio de los cuales las palabras se combinan en forma de mensajes significativos" (Duranti, 2000: 6566). Pero el significado de las palabras por separado y el de las mismas oraciones es insuficiente para la comprensión de un enunciado, que varía de acuerdo con el contexto, ya que "supone finalidades sociales. En referencia a ellas se retoman, se organizan y se interpretan las relaciones de los hombres entre sí y de los hombres con el mundo". Y estas relaciones, escribe Paoli, no son nunca estáticas, son siempre algo que quiere transformarse. Por lo tanto, "no hay semántica [...] sin la herencia del pasado, sin la acumulación histórica de la experiencia humana, que se codifica en el lenguaje y cambia con él" (Paoli, 2002, p. 19).

Pero, ¿cuáles son los alcances y la naturaleza de los nexos entre el lenguaje y el saber? Guirod (2002) afirma que el saber tiene una doble faz: un sistema epistemológico (significado) y un sistema semiológico (significante) que se expresa mediante códigos específicos, tal es el caso de las ciencias modernas. En la codificación del "saber tradicional", en cambio, se recurre a sistemas homológicos integrados, como podemos observar en la correspondencia entre la organización social, la estructura celeste y la arquitectura urbana.

Este autor marca una diferencia entre imaginar y pensar; en el primer caso operamos con imágenes, en el segundo lo hacemos con conceptos. Ma. Teresa Esquivias (2004, p. 17) define los conceptos como "categorías mentales para clasificar personas, cosas o eventos específicos con características comunes". Los sonidos vocales -las palabras- se convierten entonces en 
símbolos de los conceptos y no de los objetos percibidos (Guirod, 2002, p. 12).

Pero así como los conceptos, también las imágenes son fundamentales para la cognición y nos permiten pensar sin expresarnos verbalmente utilizando formas concretas para representar ideas complejas y abstractas (Guirod, 2002 , p. 19). Mientras nuestra cultura occidental moderna tiende a separar esos dos planos de nuestra experiencia, en las culturas 'arcaicas' las experiencias intelectiva y afectiva se integran en "prácticas ritualizadas".

Quizá el planteamiento de Guirod se antoje demasiado dual y polarizado, pero sabemos ahora con certeza que las cualidades del pensamiento racional no son universales y que existen diferentes maneras de procesar la información que recibimos a través de la experiencia sensible, relacionadas con funciones mentales distintas que el lenguaje refleja.

El lenguaje científico se basa en conceptos y se caracteriza por el elevado número de tecnicismos; el saber tradicional de las culturas "arcaicas" (es decir, no occidentalizadas) utiliza, en cambio, con frecuencia un lenguaje imaginativo y transmite conocimientos que van más allá tanto de lo racional como de lo sensible, a través del mito, la metáfora y la poesía. Esta diferencia de códigos y de categorías evidencia la dominancia de ciertas funciones mentales sobre otras y de ciertas maneras de organizar la información, sin que ello implique la superioridad de las funciones lógicas -propias del hemisferio izquierdo- sobre las que se atribuyen al hemisferio derecho.

Para concluir, quiero señalar que se asigna un bajo rendimiento a quienes asisten a escuelas donde se imparte "educación indígena" o intercultural; valdría la pena, sin embargo, introducir en la planeación educativa intercultural no solamente contenidos que reflejen sus culturas, sino pedagogías adecuadas para lenguas y formas de pensar distintas, a fin de evitar la tradicional discriminación de la que son objeto los pueblos originarios y tal vez solucionar los "problemas de aprendizaje" de buena parte de la población estudiantil mestiza.

\section{Referencias}

Buxó Rey, M. J. (1984). La cultura en el ámbito de la cognición. En Berenguer Castelary, A. et al. (1984), Sobre el concepto de cultura (pp. 33-60). Barcelona: Mitre.

Berko, J. \& Bernstein, N. (1999). Psicolingüística. Madrid: McGraw Hill / Interamericana de España.

Duranti, A. (2000). Antropología lingüística. Madrid: Cambridge University Press.

Esquivias Serrano, M. T. (2004). Creatividad: definiciones, antecedentes, aportaciones. Revista Digital Universitaria, 5(1), 1-17.

Guirod, P. (2002). La semiología. México: Siglo XXI.

Jakobson, R. (1996). El marco del lenguaje. México: Fondo de Cultura Económica.

Moreno Cabrera, J. C. (2000). La dignidad e igualdad de las lenguas. Crítica de la discriminación lingüística. Madrid: Alianza Editorial.

Ornstein, R. (1970). La psicología de la conciencia: una exploración del comportamiento humano. Madrid: Edaf.

Paoli, A. (2002). La lingüística de Gramsci. Teoría de la comunicación política. México: Ediciones Coyoacán.

Springer, S. P. \& Deutsch, G. (1994). Cerebro izquierdo, cerebro derecho. Barcelona: Gedisa.

Tryphon, A. \& Voneche, J. (2000). Piaget-Vygotsky: la génesis social del pensamiento. Argentina: Paidós. 